and to the projected building of new laboratories at Leatherhead that the council of the Association last year launched an appeal for an increase in members' subscriptions and for capital contributions. The response to the appeal has been very gratifying, and as a result the Department grant has not only been maintained but slightly increased. Capital contributions amounting to nearly $£ 200,000$ have already been promised, subject to the institution of building operations, and part has already been paid.

The whole range of the research activities of the Association is summarized in nineteen separate sections in the report. It is, however, a little difficult to form from the report an adequate picture of the relative scale of effort devoted to the various branches of work. Much emphasis is evidently placed, as in previous years, on the work on dielectrics; part of this work being carried on at the Association's laboratories at Perivale, and part under the extramural programme at the National Physical Laboratory and in the Universities of Oxford, Durham, Bristol, Liverpool and London. This research ranges from fundamental theoretical work on the physics of insulating materials to directly applicable investigations concerned with the production of stabilized capacitors. On magnetic materials, fundamental work on the production and properties of electrical sheet-steel is in progress in the laboratories of the British Iron and Steel Research Association, this work being under the control of a joint committee of this Association and the Electrical Research Association. Measurements on magnetic sheet-steel and work on permanent magnet materials are being pursued. largely as extra-mural researches.

Work on circuit breakers and circuit-breaking phenomena continues at a high level, and progress is reported in multiple break switches for high voltages. The report mentions, in passing, that "This year is the 25th anniversary of the gas-blast and the 21st anniversary of the baffle side-blast switchgear inventions of Dr. Whitney and Mr. Wedmore. The vital arc-control element in most modern high-power switchgear throughout the world, embodies in whole or some essential part their ideas and inventions". A model D.C. transmission link simulating highvoltage operation is now practically complete, and it is mentioned that "On the full-scale trial scheme a specific proposal has emerged relating to the crossChannel power link and is being considered".

The network analyser, which has been under construction for some time, has been in operation on a limited basis, and additional sections of network elements are being incorporated as components are delivered. The analyser has already proved its value in a number of researches, particularly that of restriking transients on the $132-\mathrm{kV}$. system of the British Electricity Authority. In the field of power generation, the most important problem is to raise the working temperatures of steam turbines. Extramural work at the Imperial College of Science and Technology, London, includes a programme for the measurement of the properties of steam up to $6,000 \mathrm{lb}$./sq. in. and $1,400^{\circ} \mathrm{F}$. Work is also in progress at the National Physical Laboratory on steels suitable for components operating at $1,100^{\circ} \mathrm{F}$.

During the past few years, the Electrical Research Association has been investigating the potentialities of wind-power in the I3ritish Isles. The experimental station in Orkney has been operated but is not yet in full commission, and arrangements are in hand with the College of Aeronautics for the testing of prototype equipment. Efforts are also being directed towards the development of the fuel cell, and a new research team for work on the gas cell has been establisher.

In the agricultural field, the Association has met. with considerable success in the development of grain-drying equipment, and further work is in hand on soil warming in open ground and on soil sterilization by in situ electrodes. The experimental heat. pump has been in use for some time, and a direct comparison has been made between the performance of the heat pump and that of a gas boiler installation.

Mention is made of the close liaison which the Electrical Research Association maintains with the professional institutions concerned with its spheres of work. A new departure has been made in the establishment of a programme of colloquia which are held at the Association's laboratories and to which guest speakers are invited from time to time. This year, the Association has issued ninety-four reports to members. Twenty reports have been published as papers in the technical press, together with a number of articles written by members of the staff and extra-mural research workers.

\section{SCIENCE IN GOVERNMENT SERVICES}

$\mathrm{T}$ a recent address to the American Chemical Society (see Nature, June 13, p. 1055) Dr. L. A. DuBridge, president of the California Institute of Technology, was somewhat critical of the United States Government's organization for research, and, apart from the Los Alamos Scientific Laboratory, which is operated for the Atomic Energy Commission by the University of California, expressed the opinion that the Government is not getting full value from its many existing military laboratories. Dr. O. H. Wansbrough-Jones's review of the situation in Great Britain in his William Jackson Pope Memorial Lecture, "The Scientist's Place in the Services", before the Royal Society of Arts on April 29, struck a much more confident note. He gave substantial reasons for believing that in Britain we have found means of ensuring that science, especially when devoted to defence topics, can really flourish in peacetime under government control. The position which scientists gained in the stress of war has been retained, and the scientist has now a favoured and honourable place in the Services, including the Ministry of Supply, in which he no longer has to fight for opportunities to collaborate closely with the Services in such of their problems as the scientific approach might further. He has become conscious rather of the responsibilities being imposed upon him and is wondering how far they can be discharged.

Dr. Wansbrough-Jones began by reviewing the way in which the attitude of the Services to scientific men has changed, so that in the Second World War they were no longer limited to giving the Services what they wanted rather than what the Services needed, which, as Sir Henry Tizard pointed out, is not necessarily the same thing. Apart from the influence of scientists like Tizard, Fowler and others, who had been brought intimately into the defence picture before the War, the preparation of the Technical Register and the urge to help the war effort from every scientific laboratory in the country, Dr. Wansbrough-Jones thought that there were three 
main factors responsible for scientific men achieving a position in which their powers are being fully exercised. The first is the dominant position in fields of defence science that the Government Establishments have achieved. The real knowledge of radar, service communication problems, explosives and propellants and chemical warfare is to be found in the Service Establishments, and at first even the most eminent outside scientists would be able to contribute relatively few ideas. The second factor is the increasing realization that a major scientific profession exists which might have its own contribution to make in its own terms. The third and most compelling factor of all is the practical and experimental proof, well exemplified in radar, that the scientist can contribute so much in non-technical and semitechnical fields. By the end of the War, all three Services had their own operational research teams at work in the field and at various headquarters, and in the Service Ministries and at many major commands there were senior scientists, of such rank and status that they could discuss, on equal terms with senior serving officers, the Services' problems from a scientific point of view. The general programme for research and development was evolved by such joint discussions, later to be carried out by the Ministry of Supply or of Aircraft Production, and by the Royal Naval Scientific Service. The arrangement really worked very well : the great step forward was the integration of the two disciplines, service and scientific, at a high level, so that the real problems were isolated, studied by the best scientific means available, and the results checked in the field by the method of operational research.

Generous tribute was paid by Dr. WansbroughJones to the contribution of the Services themselves to science: progress would not have been possible had not the technical and scientific knowledge and appreciation within the Services been greater than is commonly admitted. Moreover, since the War, the Services have also made advances in their own technical education. The old scientific isolation of the Government scientist has gone, and there is a good interchange both of people and results. Nor does Dr. Wansbrough-Jones think that a turnover of young scientific men, due to the attraction of higher salaries in industry, is a bad thing, provided it is not overdone. Many men who could command far higher salaries outside the Government service remain within it on account of the excellent facilities provided. Equipment in the Government Research Establishments is first-class, and he thought that much of the research and development carried out on behalf of the Services are also of great valuo to British industry as a whole and to science itself. Provided recruitment of scientific men of the right quality and the scientific education of the Services continue, he believes that the harmonious working of the Service and scientific staffs will continue, and that the best use will be made of weapons, and the very difficult task of selecting the right problems to attack will be well done. Research in these fields is admittedly expensive, and though Dr. WansbroughJones agreed that the scientist working for the Services has no easy task in seeing that costs are kept down without lowering the standard of the work, he appeared to be satisfied that Great Britain is getting good value from the average cost for fullytrained research worker, scientist or engineer-an average cost materially smaller than the latest American figures.

\section{THE CONCEPT OF PHOSPHATE BOND-ENERGY}

\author{
By DR. R. J. GILLESPIE, Dr. G. A. MAW and \\ C. A. VERNON
}

William Ramsay and Ralph Forster Laboratories, University College, London

Department of Biochemistry, St. Thomas's Hospital Medical School

$\mathrm{D}$ URING the past twenty years, it has becomo apparent that phosphorylation is one of the most fundamental processes occurring in living tissue. The role in metabolism of substances which bring about phosphorylation, such as adenosine triphosphate (ATP), is currently interpreted in terms of concepts first elaborated by Lipmann ${ }^{1}$, who divided biologically important phosphoric acid derivatives into two groups depending on whether their standard free energy of hydrolysis is large (c. - 12,000 cal. mol.-1) or small $\left(c .-2,000 \mathrm{cal}\right.$. mol. $\left.{ }^{-1}\right)$. Compounds in the first group are said to contain an 'energy-rich' or 'high-energy' $\mathrm{O}-\mathrm{P}$ or $\mathrm{N}-\mathrm{P}$ bond; those in the second group an 'energy-poor' or 'low-energy' $\mathrm{O}-\mathrm{P}$ or $\mathrm{N}-\mathrm{P}$ bond. Cleavage of 'high-onergy' bonds is imagined to liberate large amounts of free energy which may be used by the organism either to carry forward energetically unfavourable reactions or for the production of work. Catabolic processes are said to be so organized as to lead to the production of 'energyrich' compounds (for example, phosphocreatine and phosphoarginine), which function as stores of readily available energy. Anabolic processes then proceed by utilizing this energy through the mediation of adenosine tri- and di-phosphates.

This concept of 'energy-rich' phosphate bonds (which is frequently used in its literal sense) is irreconcilable with physicochemical principles. Furthermore, since the theory is actually based on free energies of hydrolysis, the relevance of classical thermodynamics to the interpretation of the detailed mechanisms of biological systems requires scrutiny.

When separate atoms combine to form molecules, that is, when chemical bonds are formed, the total energy of the system decreases. The reverse process, the dissociation of a molecule into its constituent atoms, therefore requires an expenditure of energy which is referred to as the heat of atomization. For a diatomic molecule, the bond-energy of the only bond present is defined as being equal to the heat of atomization, that is,

$\Delta H$ for the process $X_{2} \rightarrow 2 X$.

A high bond-energy, that is, a large value for $\Delta H$, indicates a strong bond and, conversely, a low bondcnergy indicates a weak bond.

In a polyatomic molecule it is usually assumed that the bond-energy of a given bond is independent of its molecular environment ${ }^{2}$, and that individual bond-energies are strictly additive. Bond-energies defined in this way, however, are no more than a convenient, although arbitrary, method of dividing up the total heat of atomization. A more useful quantity is the bond-dissociation energy, which is equal to the heat content change $\Delta H$ for the reaction $R: S \rightarrow R \cdot+S \cdot$, where $R \cdot$ and $S \cdot$ are free radicals or atoms. This quantity, unlike the bond-energy, depends on the molecular environment (ef. the $\mathrm{O}-\mathrm{H}$ bond in $\mathrm{HO}, \mathrm{H}_{2} \mathrm{O}$ and $\left.\mathrm{H}_{2} \mathrm{O}_{2}\right)^{3}$, but can be measured 